\title{
Estimating the effect of climate on water demand: Towards strategic policy analysis *
}

\author{
M Moglia ${ }^{\dagger}$ and AL Grant \\ CSIRO Land and Water, Highett, Victoria \\ MP Inman \\ CSIRO Sustainable Ecosystems, North Ryde, NSW
}

\begin{abstract}
SUMMARY: There is an expectation that many cities in Australia may experience higher temperatures and reduced rainfall in the future. Hence, to support water policy analysis there is a need for predicting water demand and how it changes in response to climate change. This paper describes a methodology to develop a model that explains month-to-month variability in water demand due to climate and weather, on the basis of using statistical methods. To achieve this, we use time series data of historical water use volumes and climate data from relevant weather stations. Applying this model together with hypothetical climate change scenarios, but without community adaptation scenarios, the results indicate that water demand will change moderately and, as may be expected, it is most sensitive to evaporation and temperature, followed by rainfall. With such scenarios, demand is shown to increase by as much as 10-20\%, but more realistic climate sequences are required to provide reliable estimates. Given availability of data, this statistical method can be used to support policy analyses in other cities.
\end{abstract}

\section{1}

\section{INTRODUCTION}

Urban areas in Australia are faced with supply shortages due to a combination of population increases, accelerated depletion of rain-fed supply sources and climatic variation. This is not a new challenge, but one that is likely to be further aggravated by expected climate change, and the lack of cheap and easily accessible supply options. For example, Kuylenstierna et al (1997) claimed that human-induced climate change is a key driving factor for future water use.

Such circumstances of increasing population and demand, combined with few remaining traditional new water supply options, are present in many of Australia's capital cities and there has been recognition of the impact already being felt of a drying climate in urban water supply systems. Beyond these existing impacts, other studies have indicated that climate change will lead to further reductions in precipitation and run-off (Howe et al, 2005) for the surface water storages that serve

\footnotetext{
* Paper W09-793 submitted 23/02/09; accepted for publication after review and revision 12/08/09.

+ Corresponding author Magnus Moglia can be contacted at magnus.moglia@csiro.au.
}

urban centres such as Melbourne. Consequently, there is recognition that strategic planning of the water supply requires an understanding of long-term changes of both the demand as well as the supply, and this requires a range of prediction and policy analysis tools (Mitchell \& White, 2003).

Consequently, the rationale for this paper is based on the following premises:

1. There is a need for planning of the water system in order to meet an increasing water demand with a potentially reducing supply.

2. The future demand is uncertain, in particular with respect to what will be the impact of changes in climate.

3. However, the adaptive response of society, ie. behavioural changes and adoption of new technologies, are in fact primarily decisions by stakeholders, such as the customers and the water utility.

In line with these premises, this paper describes a methodology for developing models that quantify baseline water demand changes in response to weather and climate in the case of no adaptation. This is a first step towards enabling "what-if scenarios" that are critical in order to inform decision making and policy making. As per the Organisation for 
Economic Co-operation and Development (OECD, 2006), this is a "future baseline" that provides a reference both as a starting point as well as allowing for comparison.

The novelty of this study is in the tuning of an established statistical approach to the particular problem and data sets that are used in this study, and overcoming the computational and interpretive challenges that this raises.

The general problem can be described as "based on historical time series, identifying a relationship linking covariates, such as climate variables, with the dependent variable which is water usage". Because we are interested in the baseline on its own, this is done without consideration of adaptive measures from customers, water utility or policy makers.

\section{LITERATURE REVIEW}

The analytic research on water demand has a number of different purposes, such as for:

- operational forecasting, as described by Zhou et al $(2001 ; 2002)$

- estimating elasticities to changes in the price of water, as reviewed by Arbues et al (2003), amongst many others

- climate correction, ie. estimating the climateneutral demand, as described by Maheepala \& Roberts (2006)

- understanding water use for the purposes of informing specific policy, as described by Willis et al (2009)

- evaluating the effect of water conservation efforts, as described by Turner et al (2005)

- assessing policy options, as described by Snelling \& Mitchell (2005)

- exploring econometric factors impacting on longterm trends in water use, as described by Babel et al (2007)

- understanding behavioural factors impacting on water use, as described by Syme et al (2004) or Rixon et al (2007).

From a methodological point of view, however, these analytical models can be classified into two main categories of approaches for water use predictions and projection, ie. individual-based bottom-up modelling, and statistical-based top-down models. Bottom-up models seek to forecast or project demand by accounting for each end use (eg. toilets, taps, sports grounds, showers, gardens, etc.), hence the term "bottom-up". They also take account of property stock, and may forecast changes in housing demographics (eg. greater uptake of multi-residential and reduction in single residential) or broader property demographics such as trends in the number of industrial properties. It is noted, however, that a new type of approach is emerging, as described by Willis et al (2009), with the advent of household metering technology, which allows for measuring water use at frequent time intervals at an individual household level.

Bottom-up models for projecting and predicting water use are the agent-based model developed by Athanasiadis et al (2005), which is used to understand the impact of pricing policies; the agent-based model by Rixon et al (2007) used to understand the role of peer pressure in water conservation; or the supply-demand planner (SDP) spreadsheet model (Snelling \& Mitchell, 2005), used at Sydney Water and a handful of Australian metropolitan water utilities, which relies on assumptions on factors like appliance stocks and rainwater tank usage, which can be used to explore various targeted demand management policies. However, while suitable for many applications, a limitation of bottom-up models is that they require understanding at the individual level of the phenomenon that the analyst is exploring. Unfortunately, in the case of individual response in water use behaviour to climate change, there is little reliable information. However, it is acknowledged that it is commonly agreed that different water uses have different sensitivity to climate. For example, outdoor water use is particularly sensitive to climate, and is an area particularly suitable for water conservation activities (Senate, 2002); in Sydney, there have been a range of programs targeting outdoor water use such as rainwater tank rebates, the Love Your Garden program, Waterwise rules and elements of BASIX, the NSW State Government's Building Sustainability Index (Sydney Water, 2008).

From the top-down, a number of prediction and projection models draw conclusions from historical observations using statistical methods, as reviewed by Maheepala et al (2002). In the work by Maidment et al $(1985 ; 1986)$ and Zhou et al $(2001$; 2002) a statistical time series model is described for predicting hourly water consumption. This model is suitable for supporting the operational management of the urban water system, and has in case studies accounted for about $80-85 \%$ of the variance in daily water consumption and about $65 \%$ of the variance in the peak hourly flows (Gato et al, 2007). This type of model uses a range of covariates and in particular shows the usefulness of including the antecedent precipitation index (API) and evaporation in the model. Similarly, Babel et al (2007) applied a multivariate econometric approach to yearly domestic water demand in Kathmandu, Nepal. The covariates were "the number of connections", "water tariff", "education level" (described as the ratio between population and number of students) and the "total annual rainfall", accounting for $96.5 \%$ of the variation.

Based on the literature review it is argued that baseline changes to the water demand can be modelled using top-down models, and that adaptive measures 
and behavioural responses are suitably modelled using bottom-up models. What-if scenarios can be constructed on the basis of baseline models based on statistical modelling combined with climate change scenarios, and models of adaptive measures and behavioural responses. Such what-if scenarios allow policy makers to explore scenarios of possible futures and the uncertainty that is inherent in such scenarios.

This paper describes a methodology for establishing baseline changes to the water use in response to climate change (using a top-down model), a question that has not been addressed in the reviewed water demand literature to date.

\section{METHODOLOGY}

This section outlines a generalised linear model (GLM) approach that addresses the research question of how water demand may vary in response to climate change. It is noted that none of the reviewed methods have addressed this question and that there is insufficient data to be able to use a bottom-up model. It is also noted that this study is focused on climate effects only, without consideration of longerterm trends or variability due to demographics. The approach will focus on a single supply zone at a time, with relatively homogeneous demographics, and using a recent time period for fitting purposes with minimal disturbance from water restrictions or any other major systems interventions.

The method chosen for this study establishes the baseline model by using GLMs fitted via regression techniques (as described by Neter et al, 2006). GLMs are statistical models similar to traditional linear regression models, but accepting a wider range of functions and probability distributions for the error term. This can be classified as a top-down modelling approach.

To translate our research question into a mathematical formulation using the GLM approach, there is a need to specify the time step, the covariates that impact on water use, the mathematical functional relationship between independent and response variables, as well as the process for selection of covariates. The underlying assumptions of the GLM also need to be evaluated in order to assess the validity of this type of model within the context.

\subsection{Time step}

The time step of a water demand model will reflect the nature of decisions or policies that are to be analysed. For example, models by Zhou et al provide relationships between weather and water use on a daily (Zhou et al, 2001) or an hourly time step (Zhou et al, 2002), which is useful for the operation of an urban water system; in particular for estimating the frequency and magnitude of peak water use events.
Babel et al (2007), however, used a yearly time step, which is more appropriate for understanding longterm water use trends.

For our purposes, temporally detailed models as described by Zhou et al $(2001 ; 2002)$ are impractical. This is primarily because of the difficulty to link climate data with accurate demand data, which is only available for longer time steps. A daily time step also introduces the need for time series modelling, due to the correlation between water uses in subsequent days even after removing temporal/ seasonal patterns. Similarly, a yearly time step as per Babel et al (2007) would limit the possible conclusions to be drawn and would also make it difficult to consider seasonal and daily variations in weather and climate. Consequently, the decision is to choose a monthly time step, which is suitable for the purpose of strategic planning.

\subsection{Covariates and mathematical function}

Climatic data from weather stations was obtained from the Australian Bureau of Meteorology (2008). However, in consideration of outputs from climate modelling (for compatibility reasons to enable whatif scenarios) only certain weather related covariates were explored (table 1).

API has been included as a covariate along with the more basic covariates (table 1). This is justified on the basis that seasonal water use is largely outdoor and so a rain day in winter has little effect compared to a rain day in summer. On this basis, API is considered a suitable predictor in our model.

The data from the Australian Bureau of Meteorology is provided on a daily time step, and this is aggregated into monthly summary variables, such as "rain days in a month" and "maximum temperature in a month". Similarly, the API is used as a covariate and is calculated using a weighted sum of a precipitation time series:

$A P I_{j}=k \cdot A P I_{j-1}+P_{j}$

$A P I_{j}$ represents the API in millimetres at day $j$, while $P_{j}$ represents the precipitation (ie. rainfall) at day $j$. $k$ is a coefficient with a value between 0.85 and 0.95 , as per Zhou et al (2001). Previous studies have used $k$ values of 0.85 (Bruce \& Clark, 1966; Zhou et al, 2002), however, in the absence of the $k$ parameter values, they were chosen for each supply zone as that providing the model with a higher significance level. To select the covariates to include in the model for each supply zone, a stepwise regression methodology has been applied that entails successively including most significant covariates and removing nonsignificant covariates. Similarly, there is a need to make choices about the type of mathematical function to use, and the key choices are between a linear equation (equation (2)), a semi-log equation 
Table 1: Covariates explored in modelling process.

\begin{tabular}{|l|l|}
\hline Input field & Reasoning \\
\hline Year & $\begin{array}{l}\text { The water use demand changes from year to year, which describes } \\
\text { non-climatic dependent shifts in water usage such as change in } \\
\text { behaviour or stocks of water appliances. The Year covariate is } \\
\text { included as a factorial effect. }\end{array}$ \\
\hline Month & $\begin{array}{l}\text { There are seasonal fluctuations in the water demand. Month is } \\
\text { included as a factorial effect. }\end{array}$ \\
\hline Temperature & $\begin{array}{l}\text { Daily maximum temperature is widely measured, easily } \\
\text { obtainable data and is likely to have a direct correlation with } \\
\text { water demand. }\end{array}$ \\
\hline Rainfall & $\begin{array}{l}\text { Intuitively, an inverse relationship between rainfall and demand is } \\
\text { expected due to rainfall reducing the need for watering of parks, } \\
\text { gardens and lawns. }\end{array}$ \\
\hline Evaporation & $\begin{array}{l}\text { Evaporation has a direct correlation with demand, which is most } \\
\text { likely due to watering of parks, gardens and lawns. For this study } \\
\text { Class A pan evaporation has been used. }\end{array}$ \\
\hline Antecedent Precipitation Index & $\begin{array}{l}\text { The API can be seen as an index for soil moisture or as } \\
\text { representing the memory for water users as to when it last rained. } \\
\text { The } k \text { value in the formula depends on the local soil conditions } \\
\text { and therefore varies depending on location. }\end{array}$ \\
\hline
\end{tabular}

(equation (3)), and a log-log equation (equation (4)), as per Babel et al (2007):

$$
\begin{aligned}
& Y=b_{0}+b_{1}\left(X_{1}\right)+b_{2}\left(X_{2}\right)+b_{3}\left(X_{3}\right)+\ldots+b_{n}\left(X_{n}\right) \\
& \ln Y=b_{0}+b_{1}\left(X_{1}\right)+b_{2}\left(X_{2}\right)+b_{3}\left(X_{3}\right)+\ldots+b_{n}\left(X_{n}\right) \\
& \ln Y=b_{0}+b_{1} \ln \left(X_{1}\right)+b_{2} \ln \left(X_{2}\right)+b_{3} \ln \left(X_{3}\right)+\ldots+b_{n} \ln \left(X_{n}\right)
\end{aligned}
$$

Here, $Y$ represents the monthly water demand (ie. the dependent variable), and $X_{i}$ represent the covariates. Additionally, interactions are also explored. This refers to when the dependent variable is a function of one covariate multiplied with another covariate (ie. for instance $Y \sim b_{i j}{ }^{*} X_{i}^{*} X_{j}$ ). The equation type is chosen that provides the model with a higher significance level.

\subsection{Assumptions}

With the choices of Normal distribution for residuals and a GLM, the methodology relies on the following assumptions:

- Residuals are randomly distributed according to the Normal distribution.

- Subsequent residuals are statistically independent and identically distributed.

- Covariates are statistically independent.

\subsubsection{Independence and distribution of residuals}

The first two model assumptions relate to the residuals that are calculated as the deviation between predicted and observed values (as described by Neter et al, 1996). If the assumption about normality of residuals does not hold, another distribution needs to be chosen. For testing this assumption, $Q-Q$ plots and Shapiro-Wilks tests are used (D'Agostino \& Stephens, 1986). If the second assumption does not hold, there would be an argument for using a time series model with an auto-regressive component, where future observations are dependent on, and usually linear combinations of historical observations. For testing this assumption, the auto-correlation function (as described by Neter et al, 1996) is calculated and evaluated.

\subsubsection{Multi-collinearity}

Regression modelling also relies on the assumption of independence between covariates, but in reality they are often correlated. This is also the situation for our case study data sets, between for example temperature and evaporation, as well as between precipitation and API.

Neter et al (1996), however, argued that on the basis that all correlated effects are attributed to only one of the correlated covariates, this does in general not reduce the capability of prediction if inferences are made within the region of observation. However, because multi-collinearity creates difficulty in separating the effects of different covariates, it does increase the standard deviation and our ability to interpret regression coefficients as rates of change (Neter et al, 1996). While multi-collinearity therefore primarily affects the actual model parameter values for individual covariates, it does not significantly affect the overall forecasting ability (Neter et al, 1996). 
For the purposes of predictions, multi-collinearity and non-linearity can potentially have a negative impact when covariates are outside the range of the observation period; and in particular therefore at the extremes of the covariate range of values.

The options for minimising the negative effects of multi-collinearity are to (i) remove one of the correlated covariates, (ii) assemble more data in order to improve the ability to separate covariate effects, or (iii) leave the model as is (Neter et al, 1996). It is considered that there is sufficient data to separate covariate effects. Nonetheless, a rule to account for multi-collinearity has been applied, keeping all covariates as candidates for inclusion into each model and only include correlated covariates if there is a significant benefit, in terms of improved adjusted multiple $R^{2}$, to do so. By doing this, the presence of multi-collinearity is minimised.

This rule is based on a balance between maximising the forecasting capacity and making sure that regression coefficients can be meaningfully interpreted as rates of change.

\subsection{Validation}

The technique that has been used to validate a model in previous water prediction approaches is to randomly remove data points from the input data set before commencing the fitting procedure, and then evaluate the predictions for the removed data points against actual observations (Zhou et al 2001; 2002; Maheepala et al, 2002; Babel et al, 2007). This approach reduces the size of the fitting data set, and more importantly does not adequately allow for evaluation of the suitability of the model outside the time period defined in the fitting data set. It is therefore suggested that two types of validation procedures are used when possible: (i) assessing the correlations between predictions and observations for removed data points, as described above; and (ii) assessing the correlations between predictions and observations for a time period subsequent to that used for prediction. Such data may only be available some time after the fitting exercise.

\section{MODEL APPLICATION: THE CASE OF SYDNEY}

To explore our methodology further it has been applied to the case of Sydney where the Metropolitan Water Plan (NSW Government, 2006) estimated that by 2031, Sydney's population of 4.12 million will have grown to 5.3 million. In recent years, Sydney has had a severe and prolonged drought with water restrictions in effect from July 1994 until September 1996, and voluntary restrictions from November 2002 and mandatory restrictions from October 2003 that are still in place at the time of writing. A relatively constant total demand, coupled with downward pressure on yield from existing surface water storages, is driving a focus on demand management in Sydney as well as an increasingly detailed assessment of future projections for the supply-demand balance.

\subsection{Data}

The data used are for the time period of 1997 until 2002, including water demand data (from 14 water supply systems) and weather data from nearby weather stations. Figure 1 shows the 14 water supply systems overlaid with the 30-year average of annual rainfall between 1961 and 1990 as published by Australian Bureau of Meteorology. The dots are the weather stations, which have long-term (more than 40 years) historic data.

Water demand is a measure of net volume flowing into a supply zone and is typically referred to as "bulk release". It is measured on a daily basis and includes total water consumption in a supply zone (ie. metered customer consumption, unmetered consumption and losses). In other words, it includes all water used by all customers in the zone as well as any losses and leakage.

To match up with this demand data, weather data has been sourced and used, which is in essence daily readings of temperature, rainfall and Class A evaporation at a number of weather stations scattered across the Sydney metropolitan area, as per table 2. This data has been supplied by the Australian Bureau of Meteorology (2008). In other words, there was no distance weighting used to match supply zones with weather station data. To deal with data gaps, alternate and nearby weather stations have been used. For example, for the Nepean supply zone, missing rainfall data has been sourced from the Camden station.

In terms of missing data, rainfall is the most sensitive climate variable, due to the high variability from station to station. Consequently, rainfall stations used in the analysis were chosen based on quality of data. Stations with minimal data gaps were used in preference to those with large data gaps, which sometimes meant using choosing stations with high quality data further away from the supply zone than stations with poor quality data. In the few locations where rainfall data gaps occurred, data was in-filled from the nearest station based on a proportion of the long term averages. In regards to evaporation and temperature, missing daily values were in-filled by averaging the previous and following day's value. Longer term data gaps were in-filled based from the nearest station with recorded data based upon a proportion of the long-term averages (similar to rainfall).

In terms of the time periods used for fitting the model, the time period 1997 until 2002 does not contain any water restrictions, and the structural 


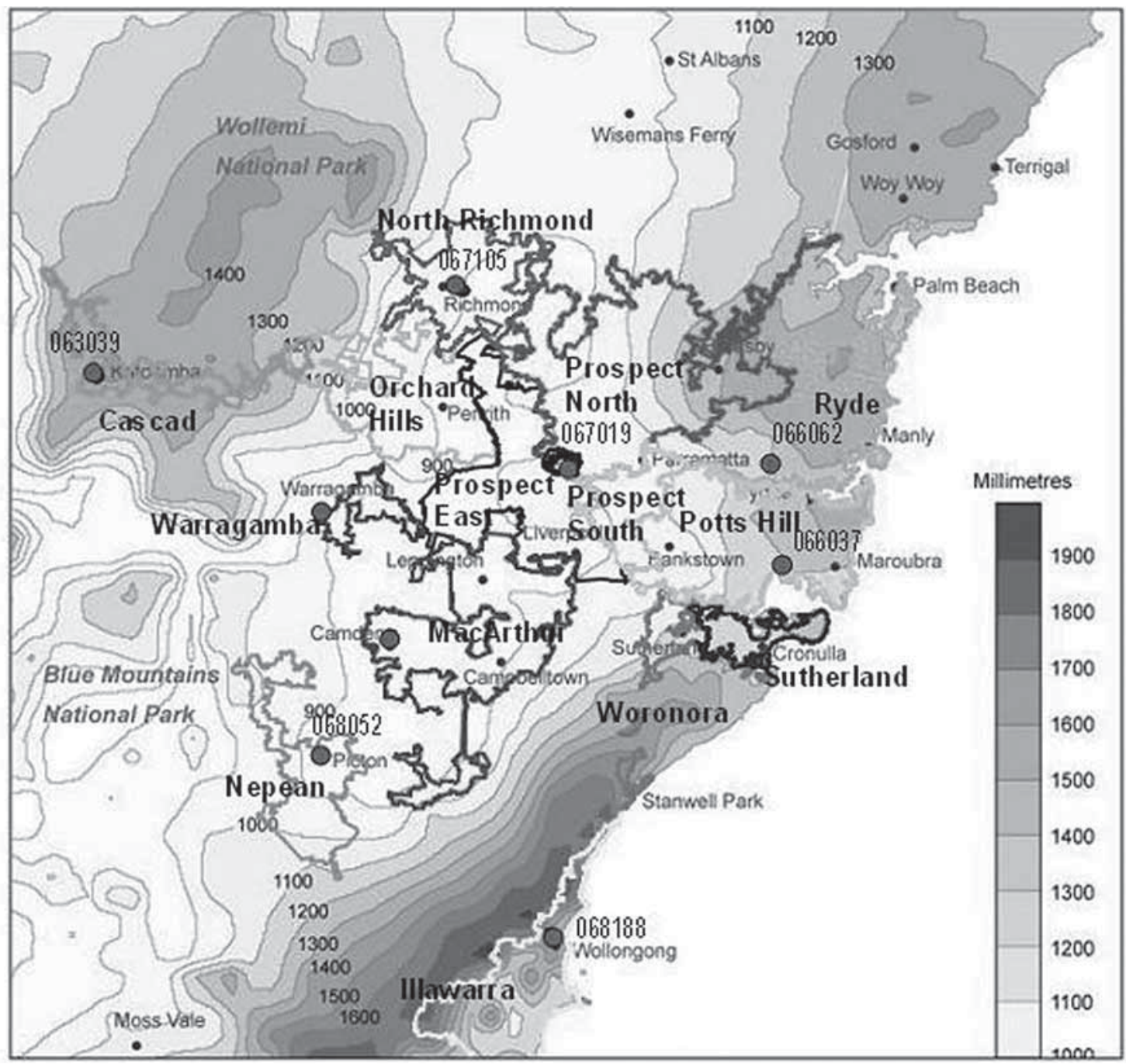

Figure 1: Water supply systems and available weather stations. Notes: This figure has been sourced from Wang (2009). The dots indicate some of the weather stations that have been used with associated station numbers (refer to table 2 notes for names).

conditions, such as relating to appliance stocks and demographics, were considered more stable. Initially, the model was fitted using the time period of 1987 until 2005, but later a more homogeneous time period was chosen, ie. 1997 until 2002.

\subsubsection{Data multi-collinearity and non-normality}

As discussed previously regarding the application of the statistical models suggested in this paper, selection of predictors must be done considering multi-collinearity and also the assumption of normality of the residual data.

Regarding multi-collinearity, the weather data has occurrences of considerable correlation between covariates, as exemplified by table 3 , which shows a correlation matrix between covariates. In this case, the correlation between temperature and evaporation is 0.87 , which must be considered high, warning us about potential multi-collinearity. The strongest correlation with systems release is with Evaporation at 0.52 , followed by Temperature at 0.42 and Minimum Monthly API at -0.27 (table 3).
Additionally, figure 2 illustrates how the raw systems release data does not follow a Normal distribution, but in fact is skewed and has a significant right tail, with a proportion of systems release values being significantly higher than the average. Although this does not necessarily invalidate the assumption of normality of residuals for the models employed (as that is dependent on the distribution of predictors also), this result may mean that the choice of a mathematical function employing a transformation (semi-log or log-log) may be more appropriate.

\subsection{Mathematical function}

The mathematical functions describing the relationship between covariates and the dependent variable were compared and evaluated based on the statistical significance of models as well as the amount of explained variation (measured via the adjusted multiple $R^{2}$ estimate). The semi-log equation (equation (3)) was found to provide the model with highest statistical significance and highest adjusted multiple $R^{2}$ for all supply zones. This finding is 
Table 2: $\quad$ Weather stations used to source climate data per supply zone.

\begin{tabular}{|c|c|c|c|}
\hline \multirow{2}{*}{ Supply zone } & \multicolumn{3}{|c|}{ Station } \\
\hline & Rainfall & Temperature & Class A evaporation \\
\hline Cascade & 063039 & 063039 & 067027 \\
\hline Illawarra & 068022 & 068188 & 066037 \\
\hline MacArthur & 068192 & 067019 & 067019 \\
\hline Nepean & 068052 & 068102 & 068047 \\
\hline North Richmond & 067105 & 067105 & 067105 \\
\hline Orchard Hills & 067105 & 067105 & 067021 \\
\hline Potts Hill & 066037 & 066037 & 066037 \\
\hline Propsect South & 067019 & 067019 & 067019 \\
\hline Prospect East & 067019 & 067019 & 067019 \\
\hline Prospect North & 067019 & 067019 & 067019 \\
\hline Ryde & 066131 & 066062 & 066062 \\
\hline Warragamba & 067027 & 067105 & 067027 \\
\hline Woronora & 066037 & 066037 & 066037 \\
\hline Sutherland & 066037 & 066037 & 066037 \\
\hline \multicolumn{4}{|c|}{$\begin{array}{l}\text { Note: The names of the weather stations that were used are Katoomba (063039), Warragamba (067027), Dapto Bowling Club (068022), } \\
\text { Wollongong Uni (068188), Sydney airport (066037), Camden (068192), Prospect Dam (067019), Picton Council Depot (068052), } \\
\text { Bowral (068102), Nepean Dam (068047), Richmond RAAF (067105), Richmond UWS Hawkesbury (067021), Riverview Observatory } \\
\text { (066131) and Observatory Hill (066062). }\end{array}$} \\
\hline
\end{tabular}

Table 3: $\quad$ Correlation matrix for weather covariates and systems release for the MacArthur supply zone.

\begin{tabular}{|l|c|c|c|c|c|c|c|c|}
\hline & $\mathrm{T}$ & $\mathrm{R}$ & $\mathrm{E}$ & $\mathrm{SR}$ & AvA & MinA & Rd & MaxT \\
\hline $\mathrm{T}$ & 1.00 & -0.06 & 0.87 & 0.42 & -0.10 & -0.12 & 0.03 & 0.89 \\
\hline $\mathrm{R}$ & -0.06 & 1.00 & -0.20 & -0.21 & 0.82 & 0.48 & 0.58 & -0.16 \\
\hline $\mathrm{E}$ & 0.87 & -0.20 & 1.00 & 0.52 & -0.29 & -0.30 & -0.11 & 0.88 \\
\hline $\mathrm{SR}$ & 0.42 & -0.21 & 0.52 & 1.00 & -0.26 & -0.27 & -0.26 & 0.44 \\
\hline AvA & -0.10 & 0.82 & -0.29 & -0.26 & 1.00 & 0.80 & 0.52 & -0.21 \\
\hline MinA & -0.12 & 0.48 & -0.30 & -0.27 & 0.80 & 1.00 & 0.48 & -0.22 \\
\hline Rd & 0.03 & 0.58 & -0.11 & -0.26 & 0.52 & 0.48 & 1.00 & -0.09 \\
\hline
\end{tabular}

somewhat perplexing given that the intuitive choice would be a linear function (equation (2)). After further exploration it was found that the semi-log function is justified because of non-linear effects from covariates such as Evaporation, with a slight tendency of a reduction in the rate of increase of systems release for higher levels of evaporation. However, in a parallel study of how climate change will impact on water use in sectors such as for residential, commercial and industrial customers (Moglia, 2009), a linear function was found to be more suitable. In future studies, suitable non-linear effects need to be explored for each covariate, but a linear function should also be considered as a serious option.

\subsection{Results}

While the method was applied to 12 supply zones in Sydney, an example of a single supply zone, ie. MacArthur, is provided here. This supply zone has 


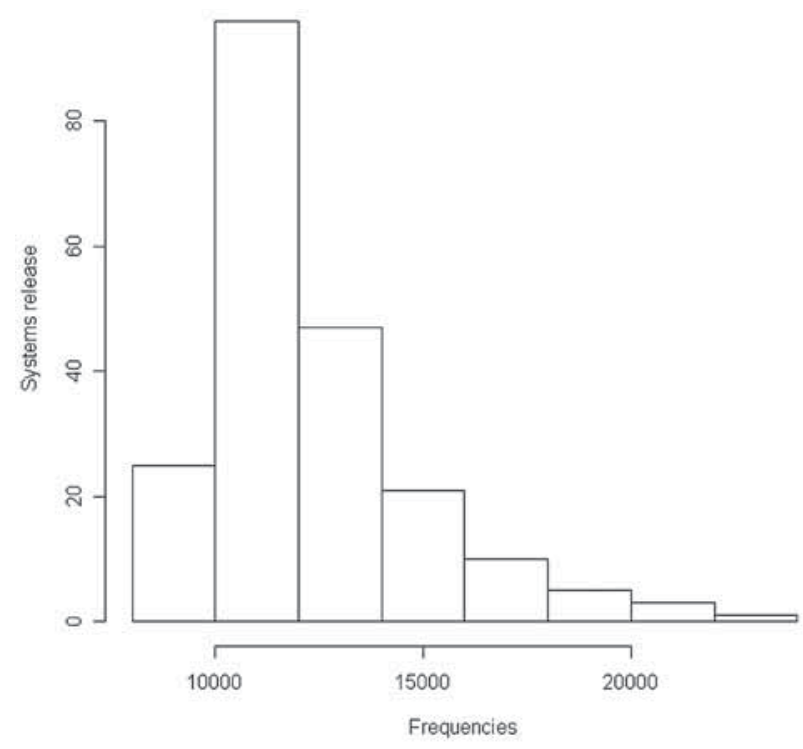

Figure 2: Histogram of systems release data for the MacArthur supply zone.

been chosen for illustrative purposes in terms of providing a typical situation, and a model with a high significance level. Using stepwise regression: (i) the semi-log function shown in equation (3) was found to be the most suitable mathematical function on the basis of overall higher significance level, and adjusted multiple $R^{2}$, of the fitted models; (ii) evaporation is shown to be the most significant predictor of water use, with the amount of explained variation, the multiple $R^{2}$ of 0.75 on its own, explaining $75 \%$ of the variation; and (iii) the average monthly API, with a $k$ value of 0.95 , is shown to be the second most important predictor, bringing the model's adjusted multiple $R^{2}$ to 0.85 .

Following these two covariates, the following are included sequentially in order of greatest marginal contribution: (i) number of rain days in interaction with a factor for each Month; (ii) a factor for each Year; and (iii) temperature averaged on a monthly basis. This brings the adjusted multiple $R^{2}$ from 0.85 to 0.96 , however, in the previous discussion about multi-collinearity, adding these covariates leads to a loss of interpretive ability. However, the decision in this case is to stop the stepwise regression with the first two covariates, ie. Evaporation and Average API, leaving the final adjusted multiple $R^{2}$ at 0.85 . These results are excellent as shown in table 4 , which includes the adjusted multiple $R^{2}$ for all supply zones for the all-inclusive model, as well as the more restrictive model.

A number of observations can be drawn from table 4. Firstly, evaporation is the most important weatherrelated predictor for water use in all supply zones, followed in most cases by either the minimum or average API. This is logical in light of the correlation matrix shown in table 3 . Secondly, the degree to which weather explains variability in water use depends on the location and context, with the multiple $R^{2}$ for the models, including only the most significant weather-related covariates ranging from as low as

Table 4: Summary of model fitting for the 12 supply zones.

\begin{tabular}{|c|c|c|c|}
\hline Supply zone & $\begin{array}{l}\text { Adjusted multiple } \\
R^{2}-\text { all significant } \\
\text { covariates }\end{array}$ & $\begin{array}{c}\text { Adjusted multiple } \\
R^{2}-\text { most significant } \\
\text { covariates }\end{array}$ & $\begin{array}{c}\text { Most significant weather-related } \\
\text { covariates }\end{array}$ \\
\hline Ryde & 0.87 & 0.75 & Evaporation, Rain days, MinAPI \\
\hline Potts Hill & 0.89 & 0.68 & Evaporation, MinAPI \\
\hline Illawarra & 0.88 & 0.79 & Evaporation, MinAPI, Rain days \\
\hline Prospect North & 0.92 & 0.59 & Evaporation, MinAPI \\
\hline Cascade & 0.58 & 0.52 & Evaporation, AvAPI, Rain days \\
\hline Macarthur & 0.91 & 0.85 & Evaporation, AvAPI \\
\hline Nepean & 0.83 & 0.59 & Evaporation, MinAPI, Rain days \\
\hline North Richmond & 0.91 & 0.77 & Evaporation, AvAPI \\
\hline Orchard Hills & 0.87 & 0.87 & Evaporation, AvAPI \\
\hline Prospect East & 0.82 & 0.33 & Evaporation \\
\hline Prospect South & 0.89 & 0.78 & Evaporation, AvAPI \\
\hline Warragamba & 0.88 & 0.69 & Evaporation, MinAPI \\
\hline \multicolumn{4}{|c|}{$\begin{array}{l}\text { Note: The all-inclusive model ("all significant covariates") includes all covariates that are significant without consideration of multi- } \\
\text { collinearity. The restrictive model ("most significant covariates") includes only the most significantly contributing covariates, in order } \\
\text { to remove multi-collinearity problems. In the case of MacArthur, the "all significant covariates" refers to the inclusion of Evaporation, } \\
\text { Average Monthly API with a } k \text {-value of } 0.95 \text { (as per equation (1)), and Rain days in interaction with a factor for each Month, a factor } \\
\text { for each Year, and Temperature. The "most significant covariates" model, however, only includes the first two of these covariates. }\end{array}$} \\
\hline
\end{tabular}


0.33 (Prospect East in the inner suburbs) to a high of 0.87 (Orchard Hills in the outer western suburbs). It is hypothesised that this has to do with the importance of outdoor water use in different zones. Finally, when including all significant covariate contributions into the models, a higher degree of explanation can be found, but this leads to issues of multi-collinearity.

\subsection{Evaluating assumptions}

To test the assumption relating to Normality of residuals, the $Q-Q$ plot test is used (as per D'Agostino \& Stephens, 1986). This is a graphical test based on comparing the theoretical and observed distributions. A straight one-to-one line indicates Normal distribution, and based on these tests it is found that the Normality of residuals is an acceptable assumption (see figure 3). To confirm this, the Shapiro-Wilks Normality test (as per D'Agostino \& Stephens ,1986) has also been used. For this test, a test statistic value for $W$ close to 1 indicates a Normal distribution, with 1 indicating perfectly Normal distribution. When $W$ is significantly smaller than 1 and the associated $p$-value is $<0.05$, the null hypothesis of Normal distribution can be rejected at the $95 \%$ confidence level. In all supply zones, the assumption of Normal distribution is acceptable with all $W$ values between 0.95 and 1 .

When evaluating the second assumption relating to independence of subsequent observations, the empirical auto-correlation function, $A(k)$, of the residuals is calculated (for more information about

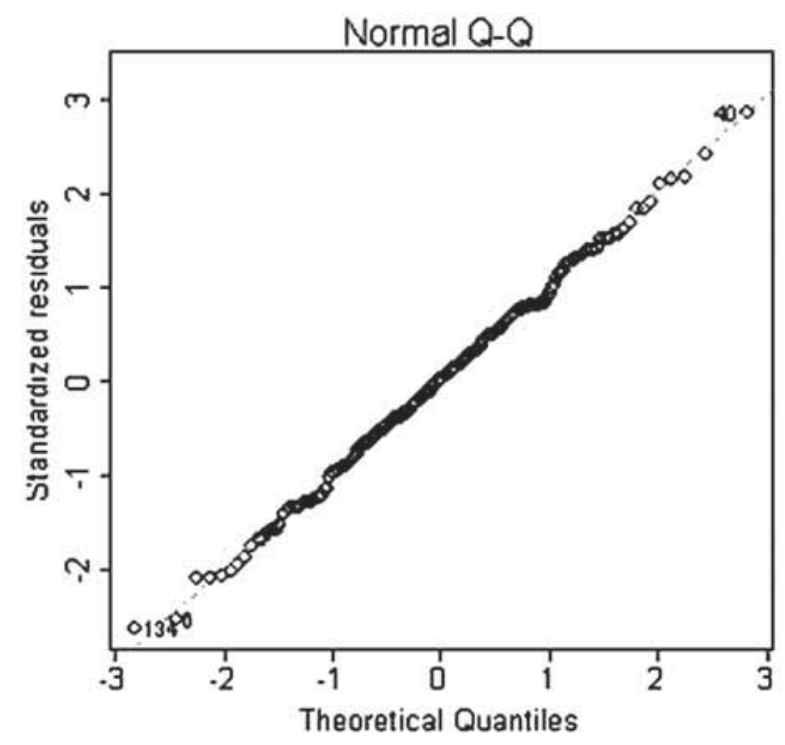

Figure 3: $\quad Q-Q$ plot for the Macarthur supply zone model. Note, in this figure the standardised residuals are mapped against the theoretical quantiles, which due to transformations ought to fall on a 1-1 line in the case that the variation in the residuals can be well described using a Normal distribution. auto-correlation functions, see Brockwell \& Davis, 1991). Values on $A(k)$ below 0.2 are considered acceptable (Neter et al, 1996). It was found that for most occasions, the auto-regressive component was reduced to below 0.2 using the GLM. The remaining auto-regressive component can be modelled using time-series modelling (as described by Brockwell \& Davis, 1991), but this was not attempted in this study as it was deemed unnecessary for our purposes.

\subsection{Validation}

To evaluate the developed models, we can compare predictions against the observations, where observations are the metered water volumes. Predictions are calculated by applying the equation (3) with the appropriate covariates as per the fitting results, which are partly shown in table 4 . On the basis of this, correlations can be calculated between predictions and observations for each supply zone, and in table 5, these correlations are shown for the calibration period.

To visualise the prediction agreement with observed system release (ie. the supply zone water use), figure 4 shows the close agreement between the two time series for the predicted and observed supply zone system release (ie. water use) between 1997 and 2002 for the Ryde supply zone. It is found that both are in relatively close agreement with the observed bulk release data, but it seems that peaks in water use are not perfectly captured with this model. We also note that in the supply zones for which the correlation is lower (ie. Woronora and Cascade), there is a greater distance between the supply zones and the weather stations that have been used, indicating the importance of using appropriate weather data.

To further explore the validity of the modelling approach, a number of data points (metered water use at different points in time) were randomly removed from the input data set before commencing the fitting procedure, and then these were evaluated against the predictions of water use for the same points in time. This validation exercise was carried out for the combined Prospect East and Potts Hill supply zones, with all validation points (ie. points not included in the fitting exercise) falling well within the $95 \%$ confidence limits. Additionally, the Pearson Product Moment Correlation, which evaluates the tendency of two variables to vary together, was calculated as 0.95 . This means that $95 \%$ of the variation in observations can be accounted for using the calculated predictions.

Finally, to evaluate the validity of the model outside the calibration period, figure 5 shows the observed versus the predicted water use for the Orchard Hills supply zone for the time period of January 2003 until April 2004, which was during a time of water restrictions in Sydney. As can be seen, the model predicts some of the variability, but is unable 
Table 5: $\quad$ Correlations between predicted and observed water use.

\begin{tabular}{|l|c|c|c|}
\hline & \multicolumn{3}{|c|}{ Correlation (1997-2002) } \\
\hline Supply zone & Pearson & Kendall & Spearman \\
\hline MacArthur & 0.97 & 0.83 & 0.96 \\
\hline Cascade & 0.83 & 0.64 & 0.80 \\
\hline Illawarra & 0.96 & 0.83 & 0.96 \\
\hline Nepean & 0.92 & 0.75 & 0.90 \\
\hline North Richmond & 0.94 & 0.77 & 0.91 \\
\hline Orchard Hills & 0.94 & 0.76 & 0.92 \\
\hline Potts Hills \& Prospect East & 0.96 & 0.82 & 0.95 \\
\hline Prospect North & 0.97 & 0.86 & 0.97 \\
\hline Prospect South & 0.96 & 0.82 & 0.95 \\
\hline Ryde & 0.95 & 0.82 & 0.96 \\
\hline Warragamba & 0.95 & 0.82 & 0.95 \\
\hline Woronora & 0.78 & 0.60 & 0.80 \\
\hline $\begin{array}{l}\text { Note: In this table, we can see the correlations between predicted and metered water use, with three types of correlations calculated, } \\
\text { ie. the Kendall tau rank correlation coefficient, the Pearson's product-moment correlation and Spearman's rank correlation coefficient. } \\
\text { Kendall and Spearman correlations are non-parametric, ie. not relying on assumptions of an underlying distribution. }\end{array}$ \\
\hline
\end{tabular}

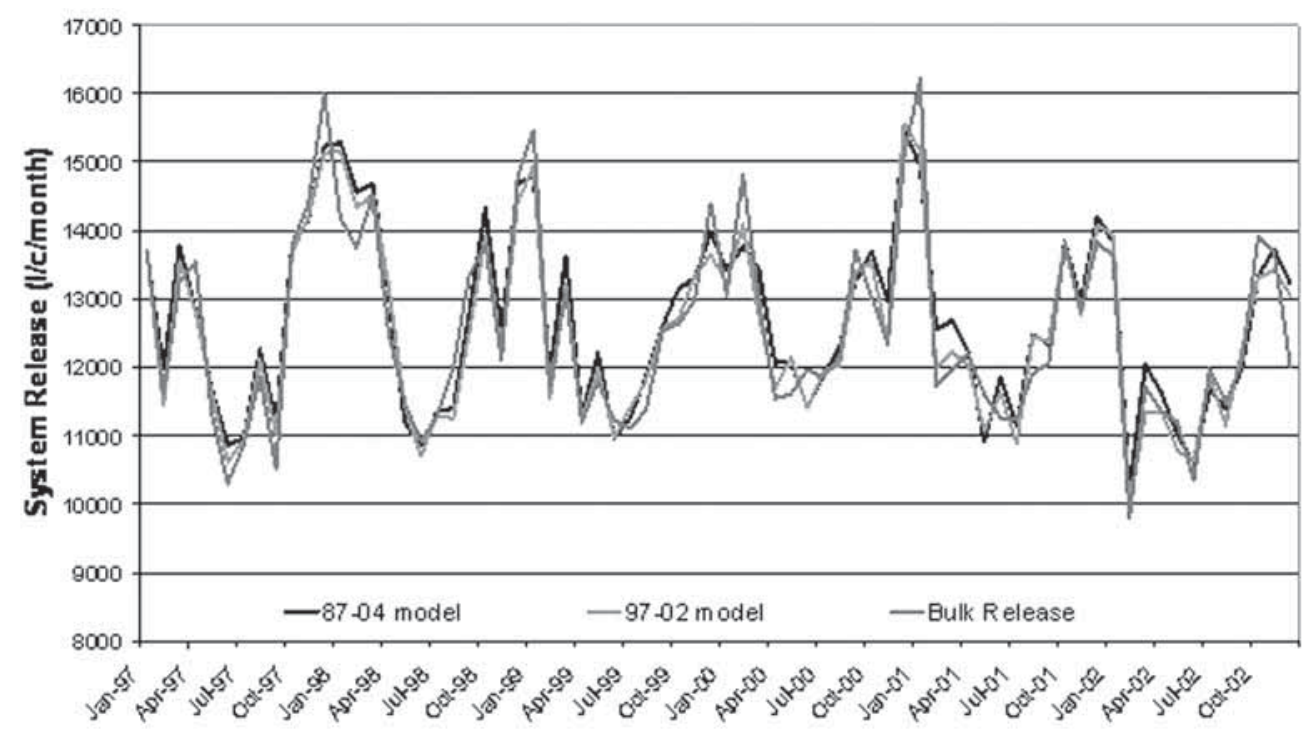

Figure 4: $\quad$ Predicted and actual system release time series for the Ryde supply zone. Note the predicted systems release is based on applying the semi-log equation using the appropriate covariates and their parameters, as per the fitted models. It is also shown how the models were fitted using different time periods, ie. 1987-2004 and 1997-2002, respectively.

to explain the full impact of water restrictions. This indicates the need for complementary models and tools to allow for scenario planning.

\subsection{Sensitivity analysis}

To explore the sensitivity of the predictive covariates to climate change, a sensitivity test was undertaken by:

- applying the 1957-1986 Sydney Airport (station \#66037) climate series to the fitted models for the supply zones of Prospect North, Potts Hill, Illawarra and MacArthur

- uniformly adjusting the temperature, evaporation, rainfall and rain days values from the climate series by $+2{ }^{\circ} \mathrm{C},+15 \%$ evaporation, $-15 \%$ rainfall and $-10 \%$ rain days, respectively, and applying the resultant climate time series to the models. (It should be noted these adjustment values are for sensitivity testing only and are assumed to be roughly equivalent for a climate change scenario, 


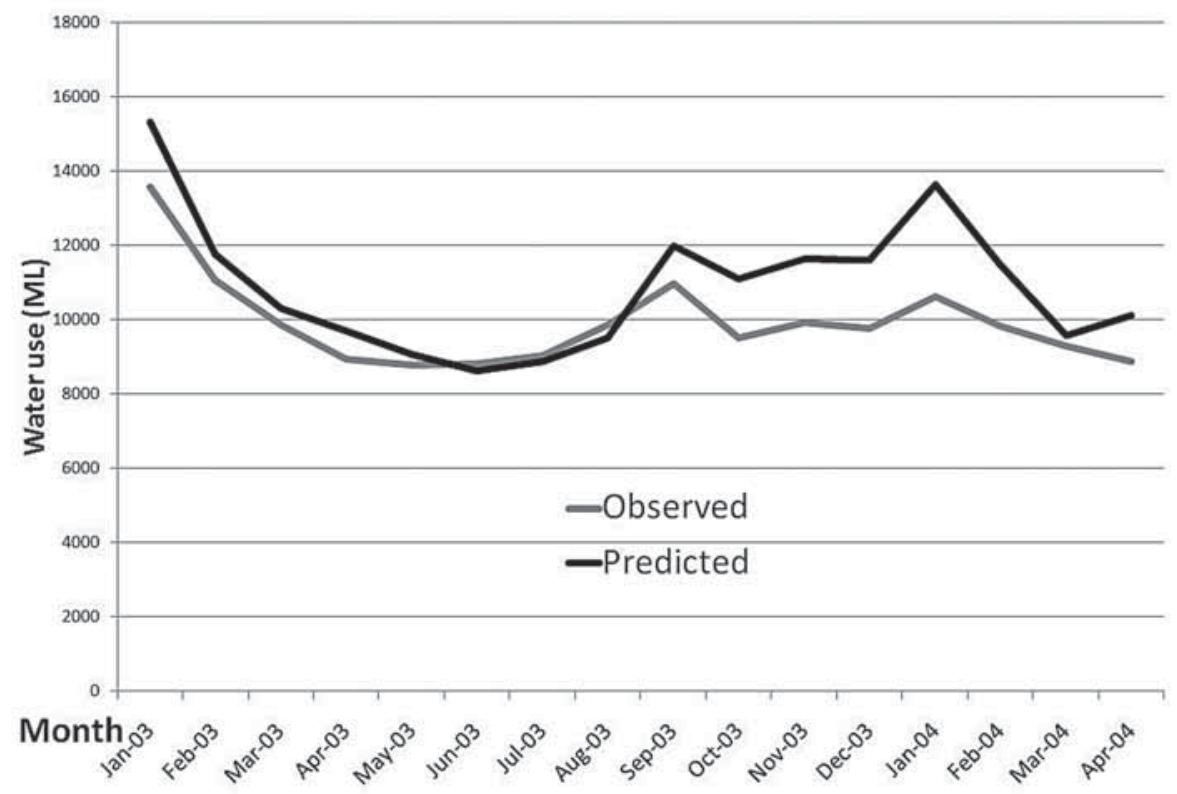

Figure 5: $\quad$ Predicted and observed system release time series for the Orchard Hills supply zone outside the calibration period.

however, it must be emphasised they do not represent predicted climate change values.)

The model was consistently most sensitive to the Class A Evaporation covariate, followed in a more tentative order by temperature, rainfall and rain days. Increasing evaporation by $15 \%$ caused an increase in model outputs of up to $13 \%$ (for Warragamba), with a typical value in the order of $7 \%$. Temperature, which is highly correlated with evaporation, was also sensitive, causing an increase of around $5 \%$ for most of the models for $+2{ }^{\circ} \mathrm{C}$. Rainfall and rain days were shown to be least sensitive, with all models showing less than $2.5 \%$ increase and most showing less than a $1 \%$ increase for a decrease of $15 \%$ in rainfall and $10 \%$ in rain days per month. Given the hypothetical climate scenarios, increases in water use ranged from around 5\% for Potts Hill to 23\% for Warragamba. The predicted impact of climate change on demand is therefore highly dependent upon supply zone. Generally, the supply zones showing the greatest sensitivity are further away from the city centre, presumably due to greater use of water outdoors in larger gardens and parks.

Given that the adjustment factors are not strictly representative of a climate change scenario, and given climate and evaporation are correlated, it can be concluded that evaporation and temperature are roughly equally sensitive. Rainfall and rain days are clearly less sensitive than evaporation and temperature.

\section{5}

\section{DISCUSSION}

Multi-collinearity causes difficulty in this study in terms of dealing with correlated covariates, and it can be seen in the results section how this impacts on the models. The dilemma is that with more covariates, we achieve a better predictive capacity, but reduce our ability to interpret results. To reduce the effect of multi-collinearity, more work is needed to identify more suitable and independent covariates for inclusion into the models.

For example, concerns were raised regarding the minimal effect of rainfall and that is mostly through the API (and due to multi-collinearity these two effects cannot be separated). There has subsequently been discussion about what drives water demand and it seems API better reflects the need for garden water use as it represents both soil moisture as well as the householder's memory of rainfall. An indication about which covariate to include is provided by the fact that API is consistently one of the most significant factors in the models, while rainfall/precipitation represents only a marginal, and often non-significant, effect.

It has also become clear that the water use response to weather and climate largely depends on the type of customer, and the next step would be to apply the GLM approach at the sectorial level, where each customer has been categorised into a sector (ie. commercial, industrial, residential, etc.). The main difficulty of this approach would be to deal with the fact that metering data is recorded on a quarterly basis, and is unsynchronised from customer to customer (ie. customers are metered on different days on a rolling schedule).

A limitation of this study is the assumption that water consumption will respond to covariates, (weather or otherwise) in the same way in the future as in the past. Additionally, behavioural responses and adaptive measures are not included, but need to be included in policy analysis in a what-if sense using bottom-up modelling. Therefore, another venue of 
future research is to combine the current models of water use to provide baseline scenarios, with bottom-up models in order to allow for adequate policy analysis.

Additionally, statistical modelling approaches are not suitable for analysing the effect of variables that are difficult or costly to measure. In our context, this often relates to the consideration of social and psychological factors, which have been shown to impact considerably on water use patterns (Troy \& Randolph, 2006; Syme \& Nancarrow, 2006; Rixon et al, 2007). Such effects may be approached in a what-if sense using for example agent-based models, although it may also be treated as separate issues outside the scope of modelling using more participatory and adaptive strategies.

\section{CONCLUSIONS}

A statistical methodology has been developed to quantify baseline water use as a function of climatic variables, and given the availability of suitable data, this methodology can also be applied to other case studies. The key contributions of the study are:

- The formulation of an important policy question into a mathematical formulation allowing for quantifying the link between weather and water use, which if combined with appropriate complementary models will allow for construction of what-if scenarios to explore possible futures.

- The application of the methodology to the supply zones in Sydney, indicating the importance of evaporation and API (indicating soil moisture) as predictors of water use. The relative importance of different factors has been surprising to several key stakeholders.

- Highlighting the contextual dependence of the relationship between water use and weather. This shows that while no generic model can be used, a generic methodology for establishing the relationship seems to be acceptable.

- Identifying approximate potential changes in water use in response to climate change by application of basic climate change scenarios. This provides an indication of whether these changes are on par with predicted changes on the supply side.

In terms of the validity of the model formulation, the assumptions of subsequent independence and Normality of error terms have been explored and found to be acceptable. However, there is a concern about correlated covariates causing issues of multicollinearity, which in turn can cause difficulty in the interpretation of results. It also noted that adaptive measures, socio-psychological factors and behavioural responses are not included in the model, and that complementary models and/or strategies are required in order to support policy analysis and the construction of what-if scenarios.
In terms of the case study results, it is clear that climatic/weather variables have an impact on water usage, however, the effect varies between supply zones. As expected, the models indicate and quantify that increased evaporation, higher temperatures and reduced rainfall will increase water use. Sensitivity analysis indicates that water demand is most sensitive to changes in evaporation and temperature. Rainfall was shown to have only a minor impact.

Additionally, while limited conclusions can be drawn without realistic climate scenarios, a $2{ }^{\circ} \mathrm{C}$ increase in temperature alone from the base case historical climate sequence, would lead to between $2 \%$ and $5 \%$ increase in water usage, while a $15 \%$ increase in evaporation alone would lead to between $2 \%$ and $11 \%$ increase in water usage, depending upon the supply zone. To evaluate more realistic changes in water usage in response to climate change, more realistic climate scenarios are required.

\section{ACKNOWLEDGMENTS}

This study is part of a NSW and Australian Government sponsored research project conducted in collaboration between the Department of Water and Energy (NSW), the Department of Environment and Climate Change (NSW), CSIRO, Sydney Water Corporation, Sydney Catchment Authority, the Commonwealth Government (through the Department of Climate Change) and the University of New South Wales.

The authors would also like to acknowledge the contribution of Yue-Cong Wang at Sydney Water for helpful discussions and help with data; Jason Martin and the Sydney Catchment Authority for data preparation and providing climatic data; The Australian Bureau of Meteorology for collecting climatic data; CSIRO Water for a Healthy Country Flagship for financial support; and David Marlow, Alan Gregory and Shiroma Maheepala of CSIRO for input through discussions.

\section{REFERENCES}

Arbues, F., Garcia-Valinas, M. A. \& MartinezEspineira, R. 2003, "Estimation of residential water demand: A state-of-the-art review", J. Socio-Econ., Vol. 32, pp. 81-102.

Athanasiadis, I. N., Mentes, A. K., Mitkas, P. A. \& Mylopoulos, N. A. 2005, "A Hybrid Agent-Based Model for Estimating Residential Water Demand", Simulation, Vol. 81, No. 3, pp.175-187.

Australian Bureau of Meteorology, 2008, Weather station directory, retrieved 17 November 2008, www. bom.gov.au/climate/averages/index.shtml?map_ type $=$ cdio\&code $=1 \#$ loc_info. 
Babel, M. S., Das Gupta, A. \& Pradhan, P. 2007, “A multivariate econometric approach for domestic water demand modelling: An application to Kathmandu, Nepal", Water Resources Management, Vol. 21, pp. 573-589.

Brockwell, P. J. \& Davis, R. A. 1991, Introduction to Time Series and Forecasting, Springer Verlag, New York.

Bruce, J. P. \& Clark, R. H. 1966, Introduction to Hydrometeorology, Pergamon Press, London.

D'Agostino, R. B. \& Stephens, M. A. 1986, Goodnessof-fit techniques, Marcel Dekker, Inc., New York.

Gato, S., Jayasuriya, N. \& Roberts, P. 2007, “Forecasting Residential Water Demand: Case Study", Journal of Water Resources Planning and Management, Vol. 133, pp. 309-319.

Grafton, R. Q. \& Kompas, T. 2006, “Sydney Water: Pricing for Sustainability", Australian National University Economics and Environment Network Working Paper EEN0609, Canberra, Australia.

Howe, C., Jones, R. N., Maheepala, S. \& Rhodes, B. 2005, Implications of Potential Climate Change for Melbourne's Water Resources, CMIT-2005-106, CSIRO, Melbourne, Australia.

Kuylenstierna, J. L. G., Bjorklund, G. \& Najlis, P. 1997, "Sustainable water futures with global implications: Everyone's responsibility", Natural Resources Forum, Vol. 21, No. 3, pp.181-190.

Maheepala, S. \& Roberts, P. 2006, "Towards development of an improved method for estimation of climate-corrected urban water use", $30^{\text {th }}$ Hydrology and Water Resources Symposium, Launceston, Australia.

Maheepala, S., Mitchell, G., Ramasamy, S. \& Whetton, P. 2002, Development of a Weather Adjustment Process for Urban Water Use, CSIRO, Melbourne, Australia.

Maidment, D. R. \& Miaou, S.P. 1986, “Daily water use in nine cities", Water Resources Research, Vol. 22, pp. 845-851.

Maidment, D. R., Miaou, S. P. \& Crawford, M. M. 1985, "Transfer function models of daily urban water use", Water Resources Research, Vol. 21, pp. 425-432.

McClellan, P. 2006, "Sydney's water supply - A reality check. Is there a need for a Public inquiry?", Supreme Court of New South Wales.

Mitchell, C. \& White, S. 2003, "Forecasting and Backcasting for Sustainable Urban Water Futures", Water, Vol. 30, No. 5.

Moglia, M., Grant, A. \& Inman, M. 2009, “How will climate change impact on water use?", Conference Proceedings of OzWater'09, Melbourne, Australia.

Neter, J., Kutner, M. H., Wasserman, W. \& Nachtsheim, C. J. 1996, Applied Linear Statistical Models, McGrawHill/Irwin.
NSW Government, 2006, 2006 Metropolitan Water Plan, Sydney, Australia.

Organisation for Economic Co-operation and Development (OECD), 2006, Key Adaptation Concepts and Terms, Paris.

Rixon, A., Moglia, M. \& Burn, S. 2007, “Exploring Water Conservation Behaviour through Participatory Agent-Based Modelling", Topics on System Analysis and Integrated Water Resource Management, Castelletti, A. \& Soncini Sessa, R. (editors), pp. 73-96, Elsevier.

Senate, 2002, The value of water: inquiry into Australia's urban water management. Report of the senate environment, communications, information technology and the arts reference committee, Parliament of the Commonwealth of Australia, Canberra, Australia.

Snelling, C. \& Mitchell, C. 2005, Melbourne End Use and Options Model, Final Report, Vol. 1, Institute for Sustainable Futures, Melbourne, Australia.

Syme, G. \& Nancarrow, B. 2006, “Social psychological considerations in the acceptance of reclaimed water for horticultural irrigation", Growing crops with reclaimed wastewater, Stevens, D., Kelly, J., McLaughlin, M. \& Unkovich, M (editors), pp. 189196, CSIRO Publishing, Collingwood, Australia.

Syme, G., Shao, Q., Po, M. \& Campbell, E. 2004, "Predicting and understanding home garden water use", Landscape Urban Plan, Vol. 68, pp. 121-128.

Thomas, F. \& Syme, G. 1988, “Estimating residential price elasticity of demand for water: A contingent valuation approach", Water Resource Research, Vol. 24, No. 11, pp. 1847-1857.

Troy, P. \& Randolph, B. 2006, “Water Consumption and the Built Environment: A Social and Behavioural Analysis", City Futures Research Centre, Sydney.

Turner, A., White, S., Beatty, K. \& Gregory, A. 2005, "Results of the largest residential demand management program in Australia", Institute for Sustainable Futures, University of Technology \& Sydney Water Corporation, Sydney, Australia.

Wang, Y.-C. 2009, “Map of Sydney supply zones and rainfall gradients", received by Inman, M., Sydney Water, Sydney, Australia.

Willis, R., Stewart, R., Chen, L. \& Rutherford, L. 2009, "Water end use consumption analysis study into Gold Coast dual reticulated household: pilot", OzWater09, AWA, Melbourne, Australia.

Zhou, S. L., McMahon, T. A. \& Wang, Q. J. 2001, "Frequency analysis of water consumption for metropolitan area of Melbourne", Journal of Hydrology, Vol. 247, pp. 72-84.

Zhou, S. L., McMahon, T. A., Walton, A. \& Lewis, J. 2002, "Forecasting operational demand for an urban water supply zone", Journal of Hydrology, Vol. 259, pp. 189-202. 

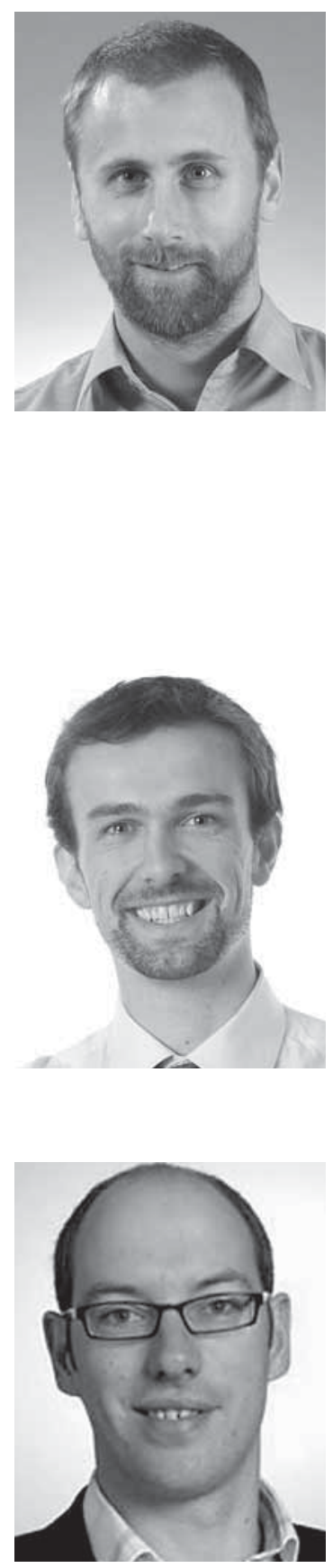

\section{MAGNUS MOGLIA}

Magnus Moglia is an interdisciplinary participatory modeller who has worked in the urban water context since 2002. He is also a statistician, and has an interest in risk analysis, complexity science, agent-based modelling, Bayesian Networks and integrated assessments. He has significant context expertise in pipeline asset performance and management, and has developed decision support systems in this area that have had a high level of adoption by the Australian water industry. More recently, he has also worked with urban water governance in developing nations, as well as developing a participatory methodology for assessing water needs in diverse locations, via the Water Needs Index. He has experience in the water, electricity and transport sectors, and is undertaking an interdisciplinary $\mathrm{PhD}$ in Environmental Management at the Australian National University, with an increasing interest in social science and stakeholder engagement, in particular in relation to water governance.

\section{ANDREW GRANT}

Andrew Grant is a Senior Environmental Engineer at BMT WBM, specialising in integrated urban water management and water sensitive urban design. He has a Bachelor of Engineering (Environmental, Hons) from the University of Melbourne and has been working in urban water management since 2000. He spent over 3 years working for Melbourne Water in land development, before spending 5 years at CSIRO as a research engineer. He has been with BMT WBM since late 2008.

\section{MATTHEW INMAN}

Dr Matthew Inman leads the CSIRO Sustainable Ecosystems Urban Systems Program. The program is exploring planning and design principles, as well as developing new generation technologies and integrated infrastructure solutions to reduce the environmental impact of cities and create healthier, more productive urban living and working spaces. Joining CSIRO in 2005, Matthew initially led the Water Smart Communities research within the Water for a Healthy Country Flagship. In March 2007, he was appointed leader of CSIRO Sustainable Ecosystems' Urban Systems research program. Prior to joining CSIRO, Matthew undertook projects on resource efficiency in the context of water and energy use within a city. Working as a Demand Analyst with Sydney Water, he developed decision support tools for managing the demand/supply balance for major urban centres. This work was adopted by the Water Services Association of Australia for use by members across Australia. Matthew has also consulted for organisations in the United Kingdom (including the Environmental Change Institute at Oxford University) on projects addressing efficient use of water and energy by households. 